\title{
EL MUNDO MITOLÓGICO CLÁSICO \\ EN EL POEMA LOS MESES DE JOSÉ DE VIERA Y CLAVIJO
}

\author{
Aurelio J. Fernández García \\ IES Viera y Clavijo \\ afergar@gmail.com
}

\section{RESUMEN}

Los Meses es un interesante poema épico de Viera y Clavijo, compuesto de 3106 versos endecasílabos que se distribuyen en doce partes: los doce meses del año. En él, Viera y Clavijo teje una perfecta tela de araña en la que los nombres de personajes de la mitología y de las leyendas del mundo griego y romano se enredan, con un riguroso cuidado literario, con numerosos saberes de la época, convirtiendo, de este modo, su composición en una verdadera minienciclopedia didáctica, llena de tecnicismos y conocimientos especializados en numerosos temas.

PALABRAS ClaVE: estaciones, meses, mitos, leyendas, mundo clásico, Viera y Clavijo.

\section{THE CLASSICAL MYTHOLOGICAL WORLD IN THE POEM LOS MESES BY JOSÉ DE VIERA Y CLAVIJO}

\section{ABSTRACT}

Los Meses is an interesting epic poem by Viera y Clavijo, make up of 3106 hendecasyllabic verses that are distributed in twelve parts: the twelve months of the year. In it, Viera y Clavijo weaves a perfect spider's web in which the names of characters from mythology and from the legends of the Greek and Roman world are entangled, with a rigorous literary care, with numerous knowledges of the time, converting, in this way, its composition in a veritable didactic mini-encyclopedia, full of technicalities and specialized knowledge on many subjects.

KEYWORDS: seasons, months, myths, legends, classical world, Viera y Clavijo.

José de Viera y Clavijo es, tal vez, uno de los personajes canarios más famosos de todos los tiempos. Aunque es más conocido por la crítica especializada por su calidad de historiador, científico, naturalista, viajero por Europa, clérigo o arcediano de la catedral de Las Palmas de Gran Canaria, cabe destacar también su faceta como poeta de la Ilustración (v. de la Nuez, 1983).

Sus primeros estudios, entre los que se encontraban la filosofía, la gramática, la literatura, los idiomas y la moral, los realizó en el convento dominico de San Benito de La Orotava. Y fueron los padres dominicos, quienes, viendo su talento e interés por los conocimientos humanísticos, lo aficionaron a la lectura de los clásicos. 
En efecto, Viera y Clavijo conoció a numerosos escritores clásicos, tanto griegos como latinos, a través de sus lecturas, siendo muchos de ellos utilizados como fuentes de conocimiento en sus diferentes obras, tanto de historia de Canarias como de carácter científico (astronomía, medicina, filosofía de la naturaleza e historia natural): Arato, Columela, Empédocles, Ennio, Estrabón, Germánico, Hesíodo, Homero, Horacio, Lucano, Lucrecio, Menilio, Parménides, Platón, Plauto, Plinio, Plutarco, Pomponio Mela, Nicandro de Colofón, Ptolomeo, Salustio, Séneca, Virgilio...

Viera y Clavijo cita en sus Memorias (Padrón Fernández, 2012) varias traducciones de obras poéticas, entre las que se encuentran algunas latinas ${ }^{1}$, religiosas y no religiosas, junto a las más abundantes del francés ${ }^{2}$. Una de las traducciones más singulares que Viera y Clavijo llevó a cabo de un autor latino es la que aparece en la «Conclusión» de su Librito de la doctrina ruraß ${ }^{3}$ (1807). De esta manera se expresa Viera y Clavijo: «Así concluyamos, si te parece, leyendo estos pasages, traducidos del libro segundo de las Geórgicas de Virgilio, desde donde dice: O fortunatos nimium. Sua si bona norint, Agricolas!... "iQué afortunado el Labrador sería, si el fondo de sus bienes conociera!...." ${ }^{4}$.

${ }^{1}$ «Breves y de escaso valor», las califica Galván González, 2002: 75.

${ }^{2}$ Para Galván González, 2002: 74, «la traducción de obras poéticas en la producción de José Viera y Clavijo (1731-1813) ocupa un espacio nada desdeñable a tenor del número de creaciones, conservadas o no, que el propio autor señala en sus Memorias». A continuación, ofrece su relación (no todas son citadas por Viera y Clavijo en sus Memorias), por fecha de composición, donde se pueden ver las traducciones latinas que hizo Viera y Clavijo de diferentes piezas poéticas: «1. Apología de las mujeres, de Charles Perrault, (Madrid, 1773); 2. Sátira V. Sobre la Nobleza, de Boileau, (Aranjuez, 1776); 3. Geórgicas, de Virgilio, libro I (París, 1777); 4. La Religión, de Louis Racine, (Madrid, 1784); 5. La Elocuencia, de La Serre, (Gran Canaria, 1787); 6. Los Jardines o el Arte de hermosear paisajes, de Delille, (Gran Canaria, 1791); 7. La Moral de la Infancia, de Carlos Morel, (Gran Canaria, 1800); 8. La Enriada, de Voltaire, (Gran Canaria, 1800); 9. El Hombre, extractado del inglés Alexander Pope, según la traducción francesa del abate Du Resnel, (Gran Canaria, 1801); 10. Aristo, soliloquio poético, de Gessner, (Gran Canaria, 1801); 11. El hombre. Sátira de Boileau, (Gran Canaria, 1802); 12. El hombre en los campos o las Geórgicas, de Delille, (Gran Canaria,1802). También se conservan otras copias con el título El Amador de los campos o las Geórgicas; 13. Prosa de difuntos Dies irae, dies illa (Gran Canaria, 1802); 14. Himno Vexilla regis (Gran Canaria, 1802); 15. Himno Pange Lingua (Gran Canaria, 1802); 16. Octava del Santísimo Sacramento, con distintas oraciones y lecciones devotas para cada día (Gran Canaria, 1802); 17. Himnos del patriarca San José (Gran Canaria, 1803); 18. Los Himnos en las festividades de los Dolores de Nuestra Señora (Gran Canaria, 1803); 19. «El Aborto», soneto francés; 20. Elegía de Tíbulo; 21. Epitafio del célebre Rafael en el Panteón de Roma; 22. "Al Relox», epitafio, de Juan de Iriarte; 23. Verso latino, puesto en el Retrato del célebre Benjamín Franklin; 24. «El Cántico de la Magnificat»; 25. «Similis factus sum pellicano solitudinis», Psalm. 101.7; 26. El Himno Sacris Solemnis; 27. "A la estatua del Gran Newton», de A. Pope; 28. Himno Ave maris stella. Asimismo, tradujo otros poemas, hoy perdidos, mencionados en sus memorias literarias, como El rizo de los cabellos robados (1803), poema heroicocómico, de Alejandro Pope y el idilio de Mme. Deshoulières, que comienza así: «Hélas, petits moutons» (1801)».

${ }^{3}$ Así continúa el título: «Para que se aficionen los Jóvenes al estudio de la Agricultura, propio del hombre». Véase, por otro lado, el comentario de Sánchez Robayna, 2005: 29.

${ }^{4}$ Verg. Georg. 2, 458-459. Como puede constatarse por estos dos versos, la traducción es un tanto libre. 
Los Meses 5 , el poema objeto de estudio de este artículo, se publicó en 1849 por la imprenta, litografía y librería La Isleña de Santa Cruz de Tenerife, siendo tenido por uno de los mejores, más ricos e incluso más originales poemas de Viera y Clavijo: él mismo lo consideraba una de sus mejores creaciones ${ }^{6}$.

Esta obra literaria pertenece al género denominado poesía didáctica, tan de moda en Francia en la segunda mitad del s. XVIII y que exportó a diversos países europeos ${ }^{7}$. El propio Viera y Clavijo fue uno de los receptores más prolíficos de esta tendencia (v. Cebrián García, 1997). En el «Prólogo» de su edición él mismo indica, de forma clara, su fuente: el poema Les Mois de Jean-Antoine Roucher ${ }^{8}$, publicado en París en 1779 ; aunque lo matiza de la siguiente manera: «es poquísimo lo que, fuera del plan y de uno u otro pensamiento, debo a la mencionada obra de Roucher» (v. Pérez Corrales, 2000: 61).

No parece que la crítica literaria de Viera y Clavijo le haya dado demasiado importancia al poema de Los Meses. En este sentido, cabe sacar a colación lo que Menéndez Pelayo escribió sobre Viera y Clavijo y Los Meses, en su Historia de las ideas estéticas en España:

Viera y Clavijo, uno de los mejores prosistas del siglo XVIII, como lo testifica su Historia de las Canarias, cultivaba las Musas contra toda la voluntad de estas sagradas doncellas; tenía, sobre todo, la manía de los poemas didácticos. Baste decir que compuso hasta siete u ocho, entre ellos, los Meses (imitación de Roucher y de los Fastos de Ovidio), las Bodas de las Plantas (que es el sistema sexual de Linneo), los Aires fijos (en que canta la extracción del gas hidrógeno, y los primeros ensayos aerostáticos), etc., etc. Para él toda materia científica era materia poética (Menéndez Pelayo, 1994: 1458).

No parece una buena crítica... Por esta razón, con este trabajo se quiere poner en consideración este poema (García Calderón, 2019: 205), haciendo especial incidencia en los conocimientos de Viera y Clavijo sobre el mundo clásico

${ }^{5}$ Para nuestro trabajo se ha seguido la edición de Pérez Corrales, 2000. Esta edición parte del original de Viera y Clavijo conservado en El Museo Canario: véase Pérez Corrales, 2000: 51-52.

${ }^{6}$ En una carta al marqués de Villanueva del Prado, datada el 28 de marzo de 1798, Viera y Clavijo alude a su poema Los Meses, escrito dos años antes, diciéndole que «lo miro como el hijo predilecto de todo lo que en esta línea ha borrajeado mi pluma»: véase Pérez Corrales, 2000: 7. Véase, además, Galván González, 1995: 540.

${ }_{7}$ Un claro ejemplo de esta influencia francesa en España es Viera y Clavijo. Junto con el teatro, los poemas didácticos fueron una de sus pasiones: Cioranescu, 1949: 312. Uno de los principales portavoces de esta influencia francesa en España es Feijoo. En ese sentido, sobre la influencia de Feijoo en Viera y Clavijo véase Hormiga, 2006: 13-14; o de Luxán y Meléndez, 2007.

${ }^{8}$ Sobre si considerar Los Meses una traducción, una adaptación, una recreación o una imitación, véase García Calderón, 2019: 208.

9 Sobre la influencia del poema de Roucher en el de Viera y Cavijo, véase, especialmente, la introducción de la edición de Pérez Corrales, 2000: 7-49. Para una posible influencia de Feijoo en la obra poética Los Meses, véase Cioranescu, 1949. 
y, sobretodo en esta ocasión, en el mundo de la mitología griega y romana, y de sus leyendas ${ }^{10}$.

Los Meses es un poema escrito en romance heroico que consta de un breve «Prólogo»; un «Elogio» de la hermana de Viera y Clavijo, María Joaquina, poetisa (Galván González, 2006); y la versión propia y particular de los doce meses del original de Jean-Antoine Roucher. Dos exergos encabezan el «Prólogo» de Los Meses, en los que Viera y Clavijo da fe ya de sus conocimientos de la lengua y literatura latinas: Per Duodena regit mundum Sol aureus Astra ("A través de las doce constelaciones del cielo, el dorado sol rige el mundo»), de Virgilio (Georg. 1, 232); y Precor, integra I Cum mente, nec turpem senectam | Degere, nec cithara carentem ("... te suplico... poder pasar mi vida en perfectas condiciones mentales y sin una vejez que me deje torpe y privado de mi cítara» ${ }^{11}$ ), de Horacio ${ }^{12}$.

El poema está conformado por 3106 versos endecasílabos, repartidos de la siguiente manera: 40 versos, en la invocación de un breve «Prólogo» inicial, y 3066 versos en los doce meses del año (Marzo: 328; Abril: 268; Mayo: 246; Junio: 314; Julio: 242; Agosto: 242; Septiembre: 240; Octubre: 222; Noviembre: 248; Diciembre: 242; Enero: 232; y Febrero: 242) ${ }^{13}$.

A través de doce cantos, correspondientes a los doce meses del año, Viera y Clavijo teje una perfecta tela de araña, en la que los nombres de personajes de la mitología y de las leyendas del mundo griego y romano se enredan entre cualidades atmosféricas y cultivos de temporada; críticas a las guerras; pensamientos animalistas; cuestiones técnicas del mar y de la pesca o nombres de famosos navegantes; descripciones de ambientes pastoriles, de la siega y trilla de las mieses; pensamientos sobre el sistema planetario y la astronomía, en los que se glorifica a Kepler y Newton; conocimientos de los vinos más famosos, tanto del mundo clásico como del contemporáneo, incluyendo los vinos canarios; referencias a la caza y su crítica; descripciones de diferentes carnavales; opiniones sobre el robo de las momias guanches o la tala indiscriminada de árboles de la selva de Doramas... En definitiva, Viera y Clavijo creyó, sin duda, que sus conocimientos del mundo clásico, aderezados con otros de

${ }^{10}$ Para este trabajo se ha decidido acotar la extensión del mismo para que su resultado no sea excesivamente largo. Pero en los versos de Los Meses, deambulan, además, dentro de esa minienciclopedia didáctica que constituye este poema, las siguientes referencias del mundo clásico: ciudades de las civilizaciones de Griega y Roma (Troya, Atenas, Roma...), países y regiones (Tracia, Arcadia, Egipto...), ríos famosos (Nilo, Tíber, Afrisio...), montes (Olimpo...), personajes de la literatura griega y romana (Melania, Tirso, Amarilis...), personajes históricos de Grecia y Roma (Artemidoro, Teócrito, Tito...) o diferentes conceptos relacionados con el mundo clásico (Paz octaviana, vellocino, tálamo...).

${ }^{11}$ La súplica la dirige al dios Apolo.

${ }^{12}$ Versos finales de la Oda 31 (no la 32 como indica por error Viera), Ad lyram: véase García Calderón, 2019: 209.

${ }^{13}$ Para la comparación del número de versos y su distribución entre Les Mois de Jean-Antoine Roucher y Los Meses de Viera y Clavijo, véase García Calderón, 2019: 210. 
carácter enciclopedista podían transmitirse también en el agradable envoltorio de la poesía didáctica que representa el poema Los Meses.

Este poema no empieza, como cabría esperar, por el orden habitual que nuestra sociedad tiene establecido para citar los meses: enero, febrero, marzo... Viera y Clavijo lo tenía claro: su poema, «su año poético», como él mismo indica en el «Prólogo», «...empieza, como el astronómico, en marzo, época en que casi todas las naciones asiáticas, y aun los primeros romanos, lo empezaban. Porque ¿̨cuál mejor época para principiar el círculo del año que la de la primavera, en que toda la natura revive? ${ }^{14} \%$. De esta manera, el poema comienza por el primer mes de esta estación: marzo.

Para este trabajo, se han agrupado los personajes mitológicos siguiendo las clasificaciones habituales de los diccionarios y manuales de mitología clásica más reconocidos por la crítica especializada. De cada personaje se indican el verso o versos en los que aparece: aquellos casos en los que se cita más de un verso es porque tiene un sentido completo o cuenta su historia mítica.

De esta forma, se han establecido los grupos que vienen a continuación para su exposición: 1. Divinidades olímpicas, 2. Musas, 3. Leyenda de Hércules, 4. Vientos, 5. Otras divinidades, 6. Otros personajes, otras leyendas, 7. Ninfas y seres de los bosques, campos y montañas, 8. Divinidades y seres marinos, 9. Amores de divinidades, 10. Divinidades específicamente romanas, y 11. Más personajes y otras "cosas» mitológicos.

Evidentemente, no cabe en este artículo extenderse en las explicaciones de los mitos y de las leyendas que aquí se citan, por lo que se dan para cada grupo unas mínimas referencias de las divinidades y de los personajes citados.

Además, para tener una referencia exacta en Los Meses de cada uno de ellos, se va a indicar, en primer lugar, el número del verso o de los versos que se citan: v. o vv.; en segundo lugar, la primera letra de la estación: $\mathrm{P}=$ Primavera, $\mathrm{E}($ estío $)=$ Verano, $\mathrm{O}=\mathrm{Otoño} \mathrm{e} \mathrm{I}=\mathrm{Invierno}$; en tercer lugar, las tres primeras letras del mes en cuestión: Ene=Enero, Feb=Febrero, Mar=Marzo, Abr=Abril, May=Mayo, Jun=Junio, Jul=Julio, Ago=Agosto, Sep=Septiembre, Oct=Octubre, Nov=Noviembre y Dic=Diciembre; y, finalmente, el orden del mes en la obra en números romanos: Marzo=I, Abril=II... ${ }^{15}$.

Viera y Clavijo indica ya sus pretensiones en la primera estrofa de su composición poética con una invocación poética, previa al desarrollo del resto de los poemas de Los Meses:

${ }^{14}$ Así lo dice en su «Prólogo»: Pérez Corrales, 2000: 62.

${ }^{15}$ Como ejemplo de esta explicación, v. 115, PJunIV. Evidentemente, se está hablando de un verso del mes de Junio, dentro de la estación de Primavera.

${ }^{16}$ Nota del propio Viera y Clavijo: «Está casi demostrado que los doce famosos trabajos o hazañas de Hércules eran una alegoría oriental de los doce signos del zodiaco, que en el discurso del año recorre el sol». 
Que la lira de Apolo otros profanen,

Que canten de un guerrero el cruel delirio,

Y diestros muelan pérfidos colores

Con que del claro Febo los doce hijos,

Triunfantes a la vez y coronadas

Sus regias frentes de diversos signos,

Monarcas son durante los espacios

En que tiene el año dividido.

¿Quiénes son los protagonistas de esta primera estrofa?: los doce meses en los que se divide el año y, en especial, Apolo (con la denominación de Febo, tan habitual en la literatura occidental), que se muestra en el v. 1, como alegoría del Sol, centro de nuestro sistema planetario.

Y cierra esta invocación, dirigiéndose a Hércules y a la musa inspiradora, tan protagonista en el resto de este poema:

A ti, padre feliz de los vivientes,

Hércules bienhechor, gigante invicto ${ }^{16}$,

A quien naturaleza debe el orden,

La armonía, el concierto, el equilibrio,

A ti, Sol admirable, a ti te invoco

Por numen de mi musa y de mis ritmos:

Haz que ellos, como tú, de todo el mundo

Abracen esta vez el laberinto.

En estos primeros versos introductorios está la razón de que en la distribución de los grupos de personajes de la mitología grecorromana antes citada se empiece por las divinidades olímpicas, por Apolo, en este caso, uno de los dioses más importantes del panteón olímpico; las musas; y la leyenda de Hércules.

\section{DIVINIDADES OLÍMPICAS}

Las divinidades olímpicas que aparecen en Los Meses son: Apolo (también con el apelativo de Febo), Ceres (Deméter en la mitología griega), Diana (Artemis en la mitología griega), Júpiter (también como Jove, una de sus denominaciones: Zeus en la mitología griega), Marte (Ares en la mitología griega), Neptuno (Poseidón en la mitología griega), Palas (denominación de Minerva y de Atenea en la mitología griega), Venus (Afrodita en la mitología griega) y Vulcano (Hefesto en la mitología griega). Viera y Clavijo no emplea, por tanto, a Juno (Hera en la mitología griega), Mercurio (Hermes en la mitología griega) y Vesta (Hestia en la mitología griega).

\section{APOLO y Febo}

«Que la lira de Apolo otros profanen»: v. 1, Prólogo.

«Pero si Apolo nos negó a nosotros»: v. 115, PJunIV. 
«Paris tañó en el Ida su zampoña, sobre el Ménalo Pan, y en la ribera | Del Anfrisio apacible el mismo Apolo I Guardó del rey Admeto las ovejas»: vv. 273-276, EJunIV. "Se deja ver en el oriente Apolo»: v. 12, ONovix.

"Con que del claro Febo los doce hijos, I Triunfantes a la vez y coronadas, I Sus regias frentes de diversos signos, I Monarcas son durante los espacios I En que tienen el año dividido»: vv. 8-12, Prólogo.

«Sus claros rayos el celeste Febo»: v. 164, PAbriI.

«Ni en su lecho de honor Febo se acuesta»: v. 188, EJunIV.

«Mi musa, girasol del claro Febo»: v. 1, IFebXII.

CERES

"Que Ceres viste de verdor lozano, I Bordado de amapolas y de ajillos»: vv. 199200, PMarI.

«Bosques de Diana, predios de Amaltea, I campos de Ceres, huertos de Pomona, I Y collados de Baco sólo fueran»: vv. 68-70, EJunIV.

"Armados de la hoz que encorvó Ceres»: v. 133, EJulv.

"Cuando aprendió de Ceres el cultivo»: v. 165, EJulv.

"Ceres trajo el arado a Siracusa»: v. 11, OOctviII.

\section{DIANA}

«Bosques de Diana, predios de Amaltea, I campos de Ceres, huertos de Pomona, I Y collados de Baco sólo fueran»: vv. 68-70, EJunIV.

"Cuando en Megara Diana cazadora»: v. 93, EAgovi.

«Cuando Diana anima sus alumnos»: v. 99, ONoviX.

JOVE (JÚPITER)

"Jove no había vibrado ningún rayo»: v. 83, PMarI.

«De Júpiter tonante, cuya herida»: v. 9, EJunIV.

«Iré por donde forja Jove el rayo»: v. 36, EAgovi.

MARTE

«¿Que el esplendor de Marte es fugitivo?»: v. 324, PMarI.

«De Martes, de Saturnos y cometas»: v. 166, EJuniv.

"Marte le debe todas sus hazañas, I Venus le debe toda su hermosura»: vv. 63-64, OOctVIII.

\section{NePTUNO}

«Brilla un tridente de bruñido acero. I Pálido el navegante huir procura, I Y Neptuno le grita: "Aguarda necio..."»: vv. 181-184, PAbrII.

"Cuando el rey del océano le dijo»: v. 221, PAbriI.

"Cesó de hablar Neptuno, y encendido»: v. 235, PAbrII.

«Bajeles soberanos, más soberbios | Que las conchas estriadas y rotundas | En que Neptuno, Tetis y Anfitrite I Viajan tal vez por la región cerúlea»: v. OOctVIII. "Pues en aquel certamen tan famoso | Que Minerva y Neptuno sostuvieron ${ }^{17}$ »: vv. 183-184, ONoviX.

\footnotetext{
a Neptuno el mar.
}

${ }^{17}$ En el reparto del mundo que hicieron los crónidas tras vencer a los titanes, correspondió 
«Neptuno ufano y de confianza lleno, | Hirió con su tridente el territorio | Que dio a luz el caballo, de la guerra ${ }^{18} »$ : vv. 187-189, ONovIX.

«El Támesis soberbio que le excede I En las fuerzas navales, pues Neptuno I Le confió, días hace, su tridente»: vv. 230-232, IDicX.

«Ve que le están llamando a grandes voces I Aquellos dos delfines que llevaron | Anfitrite a Neptuno, y que los dioses I Con el nombre de Piscis colocaron I En el zodiaco, donde el cielo corren»: vv. 12-16, IFebxII.

\section{Palas (Minerva)}

«Pero la egregia Palas con su lanza | Hizo nacer la oliva, cuyo óleo»: vv. 191-192, ONoviX.

\section{VENUS}

«Por eso a Venus bella consagraban I El mes de abril muchos antiguos pueblos; I A Venus, que era el símbolo especioso»: vv. 35-37, PAbrII.

"Así que el mes que favorece Venus I Termina en el zodiaco su campaña»: vv. 1-2, PMayIII.

«El luminar de Venus al ocaso»: v. 18, EAgovi.

«Marte le debe todas sus hazañas, I Venus le debe toda su hermosura»: vv. 63-64, OOctVIII.

\section{VULCANO \\ «Ni Vulcano su acero había esgrimido»: v. 84, PMarI.}

\section{MUSAS}

Como señala Viera y Clavijo en su «Prólogo», él ocupa sus ratos perdidos en las «musas» y por eso se decidió a invocarlas para que lo inspirasen y poder componer así su poema ${ }^{19}$. Las nueve hijas de Zeus y Mnemosine son: Clío, Euterpe,Talía, Melpómene, Terpsícore, Érato, Polimnia, Urania y Calíope (Hes. Th. 75-79). De todas ellas no cita en ningún verso a Clío, Erato, Polimnia y Calíope.

Por otro lado, el término «musa» es el referente mitológico más usado en toda la composición de Los Meses. La aparición en este grupo mitológico de la palabra «numen» se debe a su íntima relación con la palabra «musa» y con la idea de inspiración que favorece o estimula de creación poética.

${ }^{18} \mathrm{El}$ «territorio» es Atenas. La alusión a que ese territorio, es decir, Atenas, «dio a luz el caballo, de la guerra...», hace referencia a que, según algunas versiones mitológicas, el caballo de Troya fue construido con madera de olivo, símbolo de la propia Atenas.

${ }^{19}$ El canon de la épica culta aconsejaba que el poeta pidiera auxilio a la musa para que lo amparase o diese crédito a lo que se disponía a cantar: Cebrián García, 1997: 397. 


\section{MUSA}

«Cuéntame, musa, ¿cuál sería el origen»: v. 167, EJunIV.

«No lejos de Bruselas... Musa, pinta»: v. 174, OSepviI.

«Derribar vuestros troncos venerables, I Sitios queridos de las nueve hermanas I

En cuyos frondosísimos andenes I Se paseó, del numen agitado, I El divino Cairasco tantas veces. I Montaña de Doramas deliciosa ${ }^{20}$ »: vv. 114-119, IDicX.

«La musas, y las gracias y las furias»: v. 229, IDicX.

"Vuelve a animarme, musa, vuelve a darme»: v. 161, IEneXI.

«Mi musa, girasol del claro Febo»: v. 1, IFebxiI.

"Te están llamando... Vuela, musa mía»: v. 17, IFebXII.

«Descansa tú también, oh musa mía; I Rompe tu lira; enjuga tus sudores; I Doce meses cantaste en pocos días ${ }^{21}$; | Ojalá sean eternas tus canciones»: vv. 239-242, IFebXII.

\section{Melpómene, TALÍA y EUTERPE}

"Melpómene le da un nuevo hechizo | El "Cina", la "Ifigenia" y la "Merope"; | Talía, el "Misántropo" y el "Tartufo"; | Euterpe, "Alceste”, "Armida” y "Penélope”22»: vv. 163-166, IFebXII.

\section{TERPSÍCORE}

«La voz de las Sirenas, cuyas arias I Inspira entusiasmo a cuantos oyen, I El baile pantomimo, que ostentando | Toda la agilidad de Terpsícore ${ }^{23} »$ : vv. 141-144, IFebXII.

\section{URANIA}

«El gran compás de Urania? No, perdona»: v. 57, EAgoVI.

«¿Del imperio de Urania no es monarca?»: v. 5, IDicX.

\section{NUMEN}

"Derribar vuestros troncos venerables, | Sitios queridos de las nueve hermanas ${ }^{24}$ | En cuyos frondosísimos andenes I Se paseó, del numen agitado, I El divino Cairasco tantas veces. I Montaña de Doramas deliciosa»: vv. 114-119, IDicx.

${ }^{20}$ «Aquí se toca de paso y se hace la memoria de la célebre montaña de Doramas en Gran Canaria, celebrada por el ilustre poeta don Bartolomé Cairasco, y ahora lastimosamente deteriorada por las imprudentes cortas que en ella se han hecho».

${ }^{21}$ Nota del propio Viera y Clavijo: «Se empezó este poema de los Meses en 21 de mayo y se finalizó el 16 de julio de 1796».

${ }^{22}$ Nota del propio Viera y Clavijo: «Melpómene, musa de la tragedia; Talía, de la comedia; Euterpe, del drama y música, o de la ópera».

${ }^{23}$ Nota del propio Viera y Clavijo: «Musa que preside a la danza».

${ }^{24} \mathrm{~V}$. nota 20. 


\section{LEYENDA DE HÉRCULES}

A pesar de que Viera y Clavijo cita a Hércules (Heracles) en los versos introductorios, como se ha dicho anteriormente, luego parece que saca poco partido literario de él. De los doce trabajos de Hércules tan conocidos en la literatura occidental, solo hace referencia a dos de ellos, como se verá a continuación: el n.$^{\circ} 1$ «El león de Nemea» y el n. ${ }^{\circ} 11$ «Las manzanas del jardín de las Hespérides», tan vinculado a la geografía mítica de nuestras islas.

Además, hay que indicar que la aparición de Alcides, Atlante (Atlas), la Vía Láctea y Hebe en la leyenda de Hércules es suficientemente conocida: en numerosos textos literarios se utiliza la denominación de Alcides (o Alcida), para Hércules, por ser este nieto de Alceo, rey de Argos, e hijo de Anfitrión; Atlante, el hijo del titán Iapeto y de la oceánide Climene, forma parte del trabajo n. ${ }^{\circ} 11$ «Las manzanas del jardín de las Hespérides»; nuestro protagonista, según algunas fuentes mitológicas, apretó tanto el pecho de Juno (Hera) al ser amamantado por ella, que la leche saltó hasta el cielo, originándose de este modo la Vía Láctea; y Hércules, al final de su periplo como mortal y una vez convertido en inmortal, gracias a la realización de los trabajos ordenados por el rey Euristeo, ascendió al cielo, donde se casó con Hebe, hija de Zeus y Hera.

\section{HÉRCULES}

«A ti, padre feliz de los vivientes, I Hércules bienhechor, gigante invicto, I A quien naturaleza debe el orden, I La armonía, el concierto, el equilibrio, IA ti, Sol admirable, a ti te invoco I Por numen de mi musa y de mis ritmos: I Haz que ellos, como tú, de todo el mundo I Abracen esta vez el laberinto»: vv. 33-40, Prólogo.

«Hércules incansable, cuya fama I por tus doce trabajos será eterna»: vv. 47-48, EJunIV.

\section{HESPÉRIDES}

«Hespérides manzanas de continuo»: v. 88, PMarI.

\section{LEÓN DE NEMEA}

«El can de Procris y el león nemeo ${ }^{25}$ I suben al horizonte, y al mirarse I En las cadenas del celeste Alcides»: vv. 1-3, EJulv.

«Vence al león nemeo, y restituido»: v. 11, EAgovI.

\section{ALCIDES}

«El can de Procris ${ }^{26}$ y el león nemeo ${ }^{27}$ I suben al horizonte, y al mirarse I En las cadenas del celeste Alcides»: vv. 1-3, EJulv.

${ }^{25}$ Nota del propio Viera y Clavijo: «Según la fábula, el can de Procris es la Canícula o la estrella Sirio que empieza a levantarse con el sol en julio. León nemeo: es el signo de León en que el sol entra en este mes".

${ }^{26}$ Véase en el grupo «Leyendas de amor»: Procris y Céfalo.

${ }^{27}$ Nota del propio Viera y Clavijo: «Según la fábula, el can de Procris es la Canícula o la estrella Sirio que empieza a levantarse con el sol en julio. León nemeo: es el signo de León en que el sol entra en este mes». 


\section{ATLANTE}

«De la labranza, atlante del estado»: v. 289, PMarI.

«¿Los Andes del Perú, y aquel Atlante, I Que todo el cielo sobre sí sostiene?»: vv.

198-199, IDicX.

\section{VÍA LÁCTEA}

«La Vía Láctea, y el inmenso rancho»: v. 50, EAgovI.

"Y de la Vía Láctea la blancura»: v. 192, OOctVIII.

HEBE

«La ninfa Hebe, que con tanto garbo»: v. 182, EAgovI.

\section{VIENTOS}

Un papel relevante en un poema que se dedica a ensalzar las actividades agrarias, ganaderas y marinas que se dan en unas estaciones o meses determinados son los vientos. Es muy interesante el conocimiento de Viera y Clavijo sobre los vientos de la antigüedad griega y romana, considerados como divinidades por la crítica mitológica.

De esta manera, Viera y Clavijo cita a los vientos engendrados por Astreo y Eos (Aurora) ${ }^{28}$ : Céfiro, viento favorable, procedente del oeste, que traía las suaves brisas de la primavera y principios del verano, y que corresponde con el viento Favonio en latín; Bóreas, viento del norte, que corresponde con el viento Aquilón en latín; y Noto, que cita únicamente con la denominación latina de Austro, que es el viento del sur. En una ocasión Viera y Clavijo emplea el nombre del viento Hiperbóreas ${ }^{29}$, con toda probabilidad, como sinónimo del viento Bóreas. Y también en una ocasión se sirve del viento Euro, el viento del este.

Por supuesto, también está presente en Los Meses el considerado señor de los vientos, el que los calma y los agita a su antojo como se recoge en la Odisea de Homero (Od. 10, 1-76): Eolo.

\section{CÉFIRO / FAVONIO}

«Eran los vientos céfiros suaves»: v. 81, PMarI.

"Al nuevo día... El céfiro se calla...»: v. 143, PAbriI.

"Céfiro con la espiga retozando»: v. 301, EJunIV.

«Los céfiros extraños a nosotros»: v. 62, ONovIX.

«Céfiros mueven, túnicas descogen»: v. 192, IFebXII.

${ }^{28}$ Hes. Th. 379 y ss. Los otros vientos, dice Hesíodo, son hijos del monstruo Tifón: Th. 871; sin indicar ningún otro nombre.

${ }^{29}$ Hay que recordar que los hiperbóreos son un pueblo mítico, ubicado en el extremo septentrional, más allá de donde sopla el viento del norte, Bóreas. 
«Sobre las alas de un favonio amigo»: v. 30, PMarI.

«La espiga rubia que el Favonio ondea»: v. 135, EJulv.

\section{BÓREAS / AQUILÓN}

«Llama al bóreas intrépido y le manda»: v. 5, PAbriI.

«El ábrego que riñe con el bóreas»: v. 209, OOctVIII.

«Pon silencio a los bravos aquilones»: v. 11, PMarI.

«El aquilón y el austro que disputan»: v. 210, OOctVIII.

«Los hiperbóreas, euros y aquilones...»: v. 32, IFebXII.

\section{HIPERBÓREAS}

«Los hiperbóreas, euros y aquilones...»: v. 32, IFebXII.

\section{Austro}

"Ven ya del austro, ahuyenta las tinieblas»: v. 9, PMarI.

«El aquilón y el austro que disputan»: v. 210, OOctVIII.

«Él los resiste, hasta que llega el austro»: v. 33, IFebXII ${ }^{30}$.

\section{EURO}

«Los hiperbóreas, euros y aquilones...»: v. 32, IFebXII.

\section{EOLO}

«Del Eolo enojado y de sus soplos»: v. 40, ONovix.

\section{OTRAS DIVINIDADES}

«En primer lugar existió el Caos... (Hes. Th. 116 y ss.)». Casi con las mismas palabras de Hesíodo, Viera y Clavijo se hace eco de esta «jdivinidad?». Dentro de este grupo se puede ver también a Iris, la alada mensajera de los dioses y que simboliza el arco iris; a la titánide Rea y al titán Saturno; y al hijo de Zeus y Semele, Baco, el Dioniso de la mitología griega.

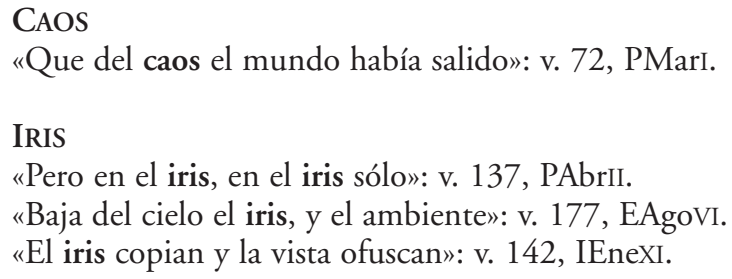

${ }^{30}$ Bóreas y Céfiro suelen ser mencionados juntos por Homero (Il. 9, 5; 23, 195, 208), al igual que Euro y Noto (Il. 2, 145; 16, 765). 
REA

«Como en tiempo de Rea y Saturno»: v. 95, PMarI.

SATURNO

"Como en tiempo de Rea y Saturno»: v. 95, PMarI.

«De Martes, de Saturnos y cometas»: v. 166, EJuniv.

«Donde el viejo Saturno va cargado I de su disforme anillo, y macilento»: vv. 38-39, EAgovi.

BACO

«Bosques de Diana, predios de Amaltea, I campos de Ceres, huertos de Pomona I Y collados de Baco sólo fueran»: vv. 68-70, EJunIv.

«Baco de yedra y pámpano vestido»: v. 303, EJunIV.

"Ya arriba Baco, que triunfante vuelve I Después de conquistar toda la India»: vv. 19-20, OSepVII.

«En las aras de Baco, ¿no prepara I Justos festines, danzas y cantigas?»: v. 115-116, OSepVII.

\section{OTROS PERSONAJES, OTRAS LEYENDAS}

¿Cómo no iba a conocer Viera y Clavijo a personajes míticos de la guerra de Troya, del viaje de los Argonautas en busca del Vellocino de oro, de Creta y su laberinto, o del mundo subterráneo grecolatino...? De esta manera, de la leyenda de Troya nombra a Paris, Néstor, Ganimedes y a los gemelos de doble naturaleza y hermanos de la famosa Helena de Troya, Cástor y Polux ${ }^{31}$, representados además por la constelación Géminis; de la leyenda de Creta, a Europa e Ícaro; de las leyendas del descenso a los infiernos y de los Argonautas, a Orfeo; y de esta última leyenda también, a Admeto y Argos.

PARIS

«Paris tañó en el Ida su zampoña, I sobre el Ménalo Pan, y en la ribera | Del Anfrisio apacible el mismo Apolo | Guardó del rey Admeto las ovejas»: vv. 273-276, EJunIv.

NÉSTOR

«Mirad aquel Néstor, como son de oro I los años de su edad, por fin lo abruman»: vv. 91-92, IEneXI.

\section{GANIMEDES}

«De aquella caña, fuente de dulzuras | Que plantó Ganimedes el dardanio | Robando de la copa de los dioses | La ambrosía y el néctar más sagrado»: vv. 227-230, EAgovI.

${ }^{31}$ También participaron en la leyenda de los Argonautas. 
CÁSTOR Y PÓLUX (y con la denominación de la constelación GÉMINIS)

«Sobre dos carros de esplendor glorioso | Cástor y Pólux a la tierra bajan, I agraciados gemelos que del día I Ilustran el imperio y lo dilatan ${ }^{32} »$ : vv. 5-8, PMayIII.

«Los Géminis vencidos, se acelera»: v. 22, EJunIV.

\section{EUROPA}

«El sol sobre la espalda de aquel bruto | Que robó a Europa con feliz denuedo»: vv. 81-82, PAbriI.

\section{ÍCARO}

"Quizá mejor Faetonte que Pilâtre, | O que Blanchard un Ícaro más cuerdo»: vv. 261-262, PAbriI.

\section{ORFEO}

"Entro en un bosquecillo donde escucho | Al Orfeo sin par de la comarca»: vv. 31-32, PMayiII.

\section{ADMETO}

«Paris tañó en el Ida su zampoña, I sobre el Ménalo Pan, y en la ribera | Del Anfrisio apacible el mismo Apolo | Guardó del rey Admeto las ovejas»: vv. 273-276, EJunIV.

\section{ARGOS}

«Gloria de Albion, tú solo fuiste el Argos»: v. 58, EAgovI.

\section{NINFAS Y SERES DE LOS BOSQUES, CAMPOS Y MONTAÑAS}

Estas divinidades suelen acompañar a divinidades importantes en sus mitemas. Las ninfas según donde habiten son de distinto tipo y reciben nombres diferentes. Viera y Clavijo cita los siguientes grupos de ninfas: amadriades o amadriadas $^{33}$, que habitan en los árboles; dríadas ${ }^{34}$; híadas, ninfas que desoladas por la muerte de su hermano Hiante se suicidaron y fueron transformadas en constelación; napeas, que habitaban en cañadas o valles; náyade $(s)^{35}$, que encarnaban las divinidades del curso del agua dulce: fuentes, pozos, manantiales, arroyos y ríos; y oréades, que protegen las grutas y las montañas. Además, en una ocasión nos muestra el término ninfas, en general.

Aparte de estas ninfas, hay otras más conocidas -y que no aparecen agrupadas- como son Calisto y Circe que también cita nuestro literato: Calisto, a la que Zeus hizo madre de Arcas, héroe epónimo de la región de Arcadia; y Circe, la famosa maga, conocida en especial por uno de los episodios más importantes de la Odisea.

\footnotetext{
${ }^{32}$ Nota de Viera y Clavijo: «Entra el sol en Géminis durante el mes de mayo».

${ }^{33}$ También son conocidas con el nombre de dríades o hamadríades.

${ }^{34}$ Véase nota anterior.

${ }^{35}$ En el poema su denominación aparece en singular.
} 
Otros seres son los grupos formados por los egipanes, divinidades rurales de origen tardío que llegaron a ser considerados como el dios Pan; faunos, que los romanos lo identificaron también en singular con el dios Pan; sátiros, cuya iconografía recuerda al ya aludido dios Pan; silvanos; y, finalmente, Sileno, un sátiro viejo, que es propenso como los sátiros a la borrachera.

\section{AMADRIADES}

«Cuando las amadriades y napeas»: v. 109, PMayiII.

\section{DRÍADAS}

«Las dríadas llorosas y confusas»: v. 114, OOctVIII.

\section{HÍADAS}

«Quebrando las Híadas ya sus urnas»: v. 21, ONovix.

\section{NAPEAS}

«Cuando las amadriades y napeas»: v. 109, PMayIII.

"Que las ninfas oreades y napeas»: v. 237, EJulv.

\section{NÁYADE}

«Es como la náyade, ninfa adulta»: v. 58, IEneXI.

\section{OREADES}

«Que las ninfas oreades y napeas»: v. 237, EJulv.

\section{NINFAS}

«Ninfas tejiendo rosas con violeta»: v. 304, EJunIV.

\section{CALISTO}

«La infelice Calisto, no queriendo»: v. 99, EAgovI.

\section{CIRCE}

«Y aún recogen las hierbas muchas Circes»: v. 119, PMayiII.

"Donde Bootes siempre aguija el carro ${ }^{36} \mid$ Donde Calisto sin cesar circula»: vv. 165-166, IEneXI.

\section{PAN}

«Paris tañó en el Ida su zampoña, I sobre el Ménalo Pan, y en la ribera | Del Anfrisio apacible el mismo Apolo | Guardó del rey Admeto las ovejas»: vv. 273-276, EJunIv. «La fístula de Pan con siete cañas»: v. 285, EJunIV.

${ }^{36}$ Nota del propio Viera y Clavijo: «Bootes es una constelación cerca de la Osa Mayor en el Polo del Norte. Calisto es la misma Osa Mayor o carro septentrional». 


\section{EGIPANES}

«Los silvanos, los faunos y egipanes»: v. 238, EJulv. «Los sátiros, los faunos y egipanes»: v. 27, OSepVII.

\section{FAUNOS}

«Los silvanos, los faunos y egipanes»: v. 238, EJulv.

«Los sátiros, los faunos y egipanes»: v. 27, OSepVII.

\section{SÁTIROS}

«Los sátiros, los faunos y egipanes»: v. 27, OSepVII.

SILENO

«Sileno el viejo con la copa brinda»: v. OSepvII.

SILVANOS

«Los silvanos, los faunos y egipanes»: v. 238, EJulv.

\section{DIVINIDADES Y SERES MARINOS}

Aparte de Poseidón, dios del mar, otro de los dioses marinos más destacables es Nereo, hijo de Gea y Ponto. Descendientes de este son las nereidas, sus cincuenta hijas, que eran divinidades marinas que cabalgaban sobre las olas montadas en delfines o a lomos de caballos marinos. Tetis y Anfitrite, que cita también Viera y Clavijo en Los Meses, desempeñan un papel protagonista en varios mitos.

Además son citados Proteo, el guardián de los rebaños de focas de Poseidón (Hom. Od. 4, 349 y ss.), que comparte con Nereo el poder de adoptar diversas formas; y las sirenas, que con su canto y su música atraían a los navegantes y hacían naufragar sus barcos.

\section{NEREO}

«Y tú, famoso Cook, de nuestros días I Marino dios, británico Nereo»: vv. 253254, PAbriI.

TETIS (NEREIDA)

«Bajeles soberanos, más soberbios I Que las conchas estriadas y rotundas I En que Neptuno, Tetis y Anfitrite I Viajan tal vez por la región cerúlea»: v. OOctVIII.

\section{ANFITRITE (NEREIDA)}

«Bajeles soberanos, más soberbios I Que las conchas estriadas y rotundas I En que Neptuno, Tetis y Anfitrite I Viajan tal vez por la región cerúlea»: v. OOctVIII. «Ve que le están llamando a grandes voces I Aquellos dos delfines que llevaron I Anfitrite a Neptuno, y que los dioses I Con el nombre de Piscis colocaron I En el zodiaco, donde el cielo corren»: vv. 12-16, IFebXII.

\section{Proteo}

«Es un proteo, que en el vasto golfo I Del universo muda de figuras, I Pero siempre conserva el mismo fondo»: vv. 36-38, ONovix. 


\section{SIRENAS}

«La voz de las Sirenas, cuyas arias I Inspira entusiasmo a cuantos oyen, I El baile pantomimo, que ostentando | Toda la agilidad de Terpsícore ${ }^{37} »$ : vv. 141-144, IFebXII.

\section{LEYENDAS DE AMOR}

\section{TISBE Y PÍRAMO}

En esta leyenda de origen babilónico, que Ovidio nos hizo llegar en sus Metamorfosis (Met. 4, 56-166), las oposiciones familiares provocan la muerte conjunta por amor de dos enamorados ${ }^{38}$.

«Ved la familia viva y numerosa, I Que busca sin cesar el alimento I En las hojas del árbol en que Tisbe I Se transformó, por Píramo muriendo»: vv. 56-60, PAbriI.

\section{PROCRIS Y CÉFALO}

En esta leyenda, recogida también por Ovidio en sus Metamorfosis (Met. 7, 688-865), Céfalo, por curiosas intervenciones divinas, clavó inmisericorde su lanza en el cuerpo de su desafortunada esposa, Procris, creyendo que era una alimaña.

"Que enamoraba a Céfalo, y dormida»: v. 9, ONovIX.

«El can de Procis y el león nemeo ${ }^{39} \mid$ suben al horizonte, y al mirarse I En las cadenas del celeste Alcides»: vv. 1-3, EJulv.

\section{BAUCIS (Y FILEMÓN ${ }^{40}$ )}

Esta es otra leyenda de amor que aparece en las Metamorfosis de Ovidio (Met. 8, 611-724). Aquí, ante los designios de los dioses, los ancianos Baucis y Filemón decidieron morir juntos: se cubrieron de follaje y solo tuvieron tiempo de decirse adiós antes de convertirse en árboles.

«La vieja Baucis, dando vuelta al huso»: v. 213, ONovIX.

\section{DIVINIDADES ESPECÍFICAMENTE ROMANAS}

Viera y Clavijo destaca también por sus conocimientos específicos de la mitología romana. En este sentido, hay que señalar que, dentro de sus viajes, destaca el que realizó a Roma en el que pudo conocer personalmente al papa Pío VI (Padrón Fernández, 2012: 22-34).

${ }^{37}$ Nota del propio Viera y Clavijo: «Musa que preside a la danza».

${ }^{38}$ Claro anticipo de la conocida obra teatral Romeo y Julieta de Shakespeare.

${ }^{39}$ Nota del propio Viera y Clavijo: «Según la fábula, el can de Procris es la Canícula o la estrella Sirio que empieza a levantarse con el sol en julio. León nemeo: es el signo de León en que el sol entra en este mes».

${ }^{40}$ Viera y Clavijo no cita en ningún verso el nombre de Filemón. 
De esta particular mitología, Viera y Clavijo cita a Flora, la soberana de las flores y esposa del viento Céfiro; Jano, la divinidad de doble aspecto, que mira al mismo tiempo hacia adelante y hacia atrás; los Lemures, las larvas y los manes, divinidades vinculadas a un lugar determinado y asimiladas, en muchas ocasiones, a divinidades infernales ${ }^{41}$; Pales, la divinidad protectora de los rebaños y patrona de los pastores, que dio nombre al monte Palatino, una de las siete colinas de Roma; y Pomona, la divinidad romana de los frutos y de los jardines.

\section{FLORA}

«Nos revelan de Flora sus secretos»: v. 117, PMarI. «¿Y la rosa, de Flora favorita?»: v. 95, PAbriI.

«De Flora el himno, con acordes voces I y con labios risueños, entonaban»: vv. 153-154, PMayIII.

"Que Flora suele hacer al año adulto»: v. 133, OSepviI.

JANO

«El viejo Jano, viendo con dos $\operatorname{caras}^{42} \mid$ Cosas pasadas, cosas aun futuras»: vv. 3-4, IEneXI.

\section{LÉMURES, MANES Y LARVAS}

«Los lémures, los manes y las larvas»: v. 247, ONovIX.

PALes

«Llegan cantando a obedecer a Pales»: v. 134, EJulv.

\section{POMONA}

«Bosques de Diana, predios de Amaltea, I campos de Ceres, huertos de Pomona, I Y collados de Baco sólo fueran»: vv. 68-70, EJuniv.

«Los huertos de Pomona y Vertumno ${ }^{43}$ »: v. 193, EAgovI.

\section{MÁS PERSONAJES Y OTRAS «COSAS» MITOLÓGICOS}

En este último grupo y funcionando como una especie de "cajón de sastre» están: Acteón, el joven cazador tebano, célebre por su cruel muerte a manos de sus propios perros; Adonis, el famoso joven del que se enamoró Afrodita y de cruel final;

${ }^{41}$ Puede resultar interesante sobre estos «seres» el trabajo de Hidalgo de la Vega, 2009.

${ }^{42}$ Nota del propio Viera y Clavijo: «Los romanos dieron a Jano la presidencia de este mes, y lo representaban con dos caras para indicar el año que acaba y el que entra. También le ponían en la mano una llave como que es el que abre las puertas del tiempo".

${ }^{43}$ Véase su leyenda en Ovidio, Met. 14, 623-696 y 765-771. 
Áglae (Aglaya), una de las tres Gracias o Cárites; Astrea, la defensora de la justicia y la virtud, transformada en la constelación Virgo ${ }^{44}$; el Cuerno de la abundancia de la diosa Fortuna que distribuye sus bienes al azar; Endimión, del que se enamoró perdidamente Selene (la Luna) y con quien tuvo cincuenta hijas; Faetonte, al que su padre Helio dejó conducir el famoso carro de fuego con funesto final; las Furias, diosas infernales romanas asimiladas a las Erinias; Febea, «De su aspecto rotundo y argentado, I Del sol hermana...»: posiblemente es una referencia a la Luna; Maya, la hija del titán Atlante y la oceánide Pleíone (por tanto, una pléyade o atlántide); $\operatorname{Mitra}(\mathbf{s})^{45}$, dios de origen iranio, cuyo culto conoció un gran éxito en la antigüedad grecorromana, compitiendo con el propio cristianismo; Momo, la personificación del sarcasmo, las burlas y la agudeza irónica, se muestra, en ocasiones, como el dios de los escritores y poetas; Orión, del que se dice que intentó violar a Artemis y que lo mató un escorpión enviado por esta, siendo catasterizados tanto Orión como el escorpión; y Triptólemo, asociado a Deméter y Perséfone en el culto de Eleusis, es hijo de Metanira y Celeo, rey de Eleusis.

\section{ACTEÓN}

«Vio que el joven Acteón la sorprendía»: v. 95, EAgovI.

ADONIS

«El sepulcro de Adonis figuraban»: v. 57, PMarI.

\section{ASTREA}

"Aquella Astrea que en el siglo de oro ${ }^{46}$ »: v. 1, EAgovI.

«La balanza de Astrea suspendida ${ }^{47} »$ : v. 2, OSepVII.

\section{ÁGLAE Y LAS GRACIAS}

«De Aglae el nombre escrito en las cortezas»: v. 302, EJunIV.

«La musas, y las gracias y las furias»: v. 229, IDicX.

\section{CUERNO DE LA ABUNDANCIA}

«El cuerno de abundancia más alegre»: v. 60, IDicX.

\section{ENDIMIÓN}

«Unas noches serenas en que baja I A estar con Endimión la amante Luna»: vv. 185-186, OOctVIII.

${ }^{44}$ Catasterismo.

${ }^{45}$ Habitualmente sin la -s.

${ }^{46}$ Nota del propio Viera y Clavijo: «La fábula enseñaba que Astrea, que había reinado durante el siglo de oro sobre la tierra, fue colocada, cuando se retiró al cielo, en aquella parte del zodiaco, de la constelación de Virgo, en cuyo signo entra el sol en agosto. Pintábanla con espigas en la mano».

${ }^{47}$ Nota del propio Viera y Clavijo: «El signo de Libra en el cual entra el sol en septiembre, según la mitología era la balanza de Astrea, hija de Júpiter y de Temis». 


\section{FAETONTE (FAETÓN):}

"Quizá mejor Faetonte que Pilâtre, I O que Blanchard un Ícaro más cuerdo»: vv. 261-262, PAbriI.

«Más de una vez hubo de ser Faetonte»: v. 4, IFebXII.

\section{FEBEA}

«Mas la amante Febea los ofusca»: v. 21, EAgovI.

FURIAS (ERINIAS)

«La musas, y las gracias y las furias»: v. 229, IDicX.

MAYA

«Haciendo hermosa el gran papel de maya»: v. 150, PMayIII.

\section{MITRAS}

«Del nacimiento de su caro Mitras ${ }^{48}$ | Eran estos los días tan solemnes I Que el persa celebraba en una gruta, I Porque creyó que de sus lobregueces I El sol allí escondido volvía al mundo»: vv. 47-51, IDicX.

\section{Mомо}

«Mirad que viene ya de Momo el coche ${ }^{49}$ »: v. 68, IFebXII.

\section{ORIÓN}

«El veneno mortífero que lanza I El Escorpión celeste, que ahora triunfa ${ }^{50}$ | De Orión en el zodiaco, no nos causen I Mortandad, epidemia ni penuria»: wv. 45-49, OOctVIII.

\section{TRIPTÓLEMO}

«Cual Triptolemo al despoblado marcha»: v. 299, PMarI.

«Del Triptolemo antiguo es propia imagen»: v. 164, EJulv.

A manera de conclusión, hay que indicar que Los Meses es un interesante poema épico en el que Viera y Clavijo plasma con un riguroso cuidado literario numerosos saberes de la época, convirtiendo, de este modo, su composición literaria en una verdadera minienciclopedia didáctica, llena de tecnicismos y conocimientos especializados en numerosos temas.

${ }^{48}$ Nota del propio Viera y Clavijo: «En Persia y posteriormente en Roma, se celebraba en el solsticio del invierno el nacimiento del sol bajo el nombre de Mitras, para lo que se adornaba una cueva, de la cual se creía místicamente renacer el sol».

${ }^{49}$ Nota del propio Viera y Clavijo: «Los antiguos representaban a Momo, el dios de las burlas, con mascarilla y una marota en la mano, que es un palo que termina en una muñeca».

${ }^{50}$ Nota del propio Viera y Clavijo: «Diose a este octavo signo del zodiaco, en el cual entra el sol por octubre, el nombre del animal ponzoñoso que quitó la vida a Orión, para denotar el aire malsano que suele correr en el otoño y ocasionar las epidemias». 
La capacidad de Viera y Clavijo para entrelazar en 3106 versos endecasílabos estaciones del año y sus meses con todos estos contenidos, junto con personajes de los mitos y de las leyendas grecorromanas dan idea de la capacidad intelectual de nuestro ilustre e ilustrado literato.

El caudal de conocimientos del mundo clásico queda evidente en este trabajo. Como en tantas ocasiones, las referencias clásicas aportan, como técnica argumentativa, una auctoritas specialis a Los Meses, incrementando con suficiente evidencia la calidad literaria del poema.

Los contenidos de la literatura de Grecia y Roma se presentan en Los Meses casi como una especie de captatio benevolentiae para explicar lo que realmente le interesaba a Viera y Cavijo: difundir cultura y difundir educación entre sus coetáneos.

\section{REFERENCIAS BIBLIOGRÁFICAS}

CEBrián GarCía, J. (1997): «El héroe en la poesía didáctica de Viera y Clavijo», Nueva Revista de Filología Hispánica (NRFH) 45 (2): 391-408.

CiORANeSCU, A. (1949): «José Viera y Clavijo y la cultura francesa», Revista de Historia 88 (XV): 293-329.

GarCía CALDERÓN, A. (2019): «Les Mois de Jean-Antoine Roucher y la versión de José de Viera y Clavijo Los Meses, Çédille, revista de estudios franceses 15: 189-217.

Galván GonZÁlez, V. (1995): «La poesía imitada de José de Viera y Clavijo», Anuario de Estudios Atlánticos 42: 519-557.

Galván GonZÁlez, V. (2002): «La poesía traducida de Viera y Clavijo», DICENDA. Cuadernos de Filología Hispánica 20: 73-103.

Galván GonZÁlez, V. (2006): La obra poética de María Joaquina de Viera y Clavijo, Departamento de Ediciones de la Consejería de Cultura y Patrimonio Histórico del Cabildo de Gran Canaria, Gran Canaria.

Hidalgo de la Vega, M. J. (2009): Larvas, lemures, manes en la demonología de apuleyo y las creencias populares de los romanos, Universidad de Huelva, Huelva.

Hormiga, F. (2006): Noticias de José de Viera y Clavijo, Gobierno de Canarias, Gran Canaria.

LUXÁN Y MELÉNDEZ, S. DE (2007): Ensayo de una biblioteca ilustrada. La librería virtual de Viera y Clavijo, Real Sociedad Económica de Amigos del País de Gran Canaria, Gran Canaria.

Menéndez Pelayo, M. (1994): Historia de las ideas estéticas en España. Madrid, Consejo Superior de Investigaciones Científicas. Edición facsímil, vol. I.

NuEZ, S. DE LA (1983): «Viera y Clavijo, poeta ilustrado», Anales de Literatura Española 2: 155-175.

PAdrón Fernández, R. (ed.) (2012): Memorias. José de Viera y Clavijo, Ediciones Idea, Tenerife.

PAdRÓN FERNÁNDEZ, R. (2019): «Europa a la vista: Viera y Clavijo en el Gran Tour», Viera y Clavijo. De isla a continente (Exposición / Coordinación R. PADRón FERnÁndeZ), Viceconsejería de Cultura y Deportes del Gobierno de Canarias, Tenerife.

Pérez Corrales, J. M. (ed.) (2000): Los Meses. José de Viera y Clavijo, Ediciones del Cabildo de Gran Canaria, Madrid.

SÁnchez RobaYna, A. (2005): «Canarias: la traducción como tradición», Anuario de Estudios Atlánticos 51: 21-44. 
